\title{
Penerapan Problem Based Learning (PBL) dengan Pemberian Biografi Ilmuwan Pada Mata Kuliah Fisika Dasar I: Dampak Sikap Ilmiah dan Motivasi belajar
}

\author{
Hadma Yuliani \\ Program Studi Tadris (Pendidikan) Fisika, FTIK IAIN Palangka Raya Jl. G.Obos, Komplek \\ Islamic Centre, Palangka Raya, Kalimantan Tengah, Indonesia. \\ Email Korespondensi: hadma.yuliani@iain-palangkaraya.ac.id
}

\begin{tabular}{|c|c|}
\hline Article Info & Abstract \\
\hline $\begin{array}{l}\text { Article History } \\
\text { Received: 03 June } 2021 \\
\text { Revised: } 30 \text { June } 2021 \\
\text { Published: } 30 \text { June } 2021\end{array}$ & \multirow{2}{*}{$\begin{array}{l}\text { The application of PBL along with the biographies of scientists in learning } \\
\text { physics is expected to have an impact on scientific attitudes and student } \\
\text { motivation to learn. The objectives of this study were: (1) To find out the } \\
\text { improvement of students' scientific attitude after PBL was applied by giving } \\
\text { scientists biographies in Basic Physics I course; (2) To find out the increase in } \\
\text { students' learning motivation after PBL by applying the biographies of } \\
\text { scientists in the Basic Physics I course. This study used a quantitative } \\
\text { approach with descriptive research type. The data collection technique used a } \\
\text { questionnaire for scientific attitudes and learning motivation. The results } \\
\text { showed: (1) There was an increase in the ability of scientific attitudes by } \\
\text { applying PBL by giving scientists biographies in the Basic Physics I course in } \\
\text { the medium category with an N-gain value of } 0.523 \text { and (2) There was an } \\
\text { increase in learning motivation by applying. }\end{array}$} \\
\hline $\begin{array}{l}\text { Keywords } \\
\text { writing instructi } \\
\text { prism journal; } \\
\text { article template }\end{array}$ & \\
\hline Informasi Artikel & Abstrak \\
\hline $\begin{array}{l}\text { Direvisi: } 30 \mathrm{Ju} \\
\text { Dipublikasi: } 30\end{array}$ & \multirow{2}{*}{$\begin{array}{l}\text { Penerapan PBL disertai biografi ilmuwan pada pembelajaran fisika } \\
\text { diharapkan memberikan dampak terhadap sikap ilmiah dan motivasi belajar } \\
\text { mahasiswa. Tujuan Penelitian ini adalah: (1) Untuk mengetahui peningkatan } \\
\text { sikap ilmiah mahasiswa setelah diterapkan PBL dengan pemberian biografi } \\
\text { ilmuwan pada mata kuliah Fisika Dasar I; (2) Untuk mengetahui peningkatan } \\
\text { motivasi belajar mahasiswa setelah PBL dengan diterapkan pemberian } \\
\text { biografi ilmuwan pada mata kuliah Fisika Dasar I. Penelitian in } \\
\text { menggunakan pendekatan Kuantitatif dengan jenis penelitian deskriptif. Teknik } \\
\text { pengumpulan data menggunakan angket untuk sikap ilmiah dan motivasi } \\
\text { belajar. Hasil penelitian menunjukkan: (1) Terdapat peningkatan kemampuan } \\
\text { sikap ilmiah dengan menerapkan PBL dengan pemberian biografi ilmuwan } \\
\text { pada mata kuliah Fisika Dasar I kategori sedang dengan nilai } N \text {-gain } 0,523 \\
\text { dan (2) Terdapat peningkatan motivasi belajar dengan menerapkan. }\end{array}$} \\
\hline $\begin{array}{l}\text { Kata kunci } \\
\text { Petunjuk penulis } \\
\text { Jurnal prisma; } \\
\text { template artikel }\end{array}$ & \\
\hline
\end{tabular}

Sitasi: Yuliani, H. (2021). Penerapan Problem Based Learning (PBL) dengan Pemberian Biografi Ilmuwan Pada Mata Kuliah Fisika Dasar I: Dampak Sikap Ilmiah dan Motivasi belajar. Kappa Journal, 5(1), 128-136.

\section{PENDAHULUAN}

Program Studi Tadris (Pendidikan) Fisika merupakan salah satu program studi yang terdapat di IAIN Palangka Raya. Program Studi Tadris (Pendidikan) Fisika merupakan program studi yang tidak terlalu besar memiliki peminat yang berkuliah di program studi tersebut. Hal ini berdasarkan, data mahasiswa yang berkuliah di program studi tadris (Pendidikan) Fisika selama empat tahun terakhir yaitu tahun 2015 sebanyak 10 mahasiswa; 
tahun 2016 sebanyak 13 mahasiswa; tahun 2017 sebanyak 27 mahasiswa, dan tahun 2018 sebanyak 31 mahasiswa. Walaupun mengalami peningkatan jumlah mahasiswa tadris (pendidikan) fisika setiap tahunnya .Akan tetapi, peminat yang masuk prodi tadris (pendidikan) fisika lebih sedikit dari program studi lain.

Berdasarkan hasil wawawancara yang dilakukan dengan mahasiswa yang memilih program studi tadris (pendidikan) fisika di Program Studi Tadris (Pendidikan) Fisika IAIN Palangka Raya menyatakan program studi tadris (pendidikan) fisika dianggap sulit dan banyak rumus serta perhitungannya. Berdasarkan wawancara dengan mahasiswa baru yang kuliah hanya sebagian kecil dari sekolah asal mahasiswa yang mengambil pilihan program studi tadris (pendidikan) Fisika. Sehingga, sedikit saja dari mahasiswa yang termotivasi masuk program studi tadris (pendidikan) fisika. Hal ini dikarenakan, salah satu kurangnya penanaman biografi ilmuwan untuk dimiliki peserta didik agar mempunyai semangat pantang menyerah yang dimiliki ilmuwan.

Pemberian biografi ilmuan diperlukan pada pembelajaran fisika. Hal ini sejalan, penelitian mengenai pengembangan media pembelajaran interaktif dengan memberikan materi gambaran kepada mahasiswa terhadap temuan maupun biografi ilmuwan kimia berpengaruh terhadap perkembangan kimia di dunia yang memberikan dampak terhadap motivasi belajar mahasiswa (Priyambodo, Wiyarsi, \& Sari, 2012). Hal ini menunjukkan, pemberian biografi tokoh memberikan pengaruh terhadap motivasi belajar (ROFIQOTURROHMAH, 2019).

Pemberian biografi Ilmuwan berkaitan dengan perkembangan konsep fisika melalui konteks sejarah fisika yang melibatkan Ilmuwan Fisika dan teknologi yang digunakan manfaat sejarah Fisika. Dengan mempelajari perkembangan konsep dan biografi ilmuwan agar karakter ilmuwan dapat berkembangan melalui pengintegrasian dalam pembelajaran Fisika dengan pengenalan tokoh-tokoh Fisika (Sinurat, 2017).

Pemberian biografi ilmuwan perlu didukung model pembelajaran yang berpusat pada peserta didik. Salah satu model pembelajaran yang berpusat pada peserta didik yaitu model PBL. Model PBL dibentuk dengan landasan teori-teori pembelajaran konstruktivime dan pembelajaran berdasarkan pengalaman. Model PBL merupakan salah satu cara yang dapat digunakan oleh pendidik dalam usaha membatu peserta didik menjadi kompeten dalam memecahkan masalah (Fauziah, Abdullah, \& Hakim, 2013) (Mayasari, Kadarohman, Rusdiana, \& Kaniawati, 2016) (Nugraha, Suyitno, \& Susilaningsih, 2017).

Model PBL merupakan suatu proses pembelajaran menghadapkan peserta didik dengan permasalahan nyata yang terjadi di lingkungan sekitar. Sehingga, peserta didik tidak hanya belajar mengenai pengetahuan akan tetapi merasakan dan mengalami sendiri (Khoirunisa, Rohmadi, \& Yuliani, 2020). Beberapa kelebihan Model PBL antara lain berpengaruh hasil belajar (Shinta, Fatmawati, \& Nasir, 2020) (Wajdi, 2018), aktivitas belajar peserta didik (Khoirunisa, Rohmadi, \& Yuliani, 2020), berpengaruh terhadap berpikir kritis peserta didik (Yunita, Zahara, \& Sahidi, 2020), berpengaruh terhadap sikap ilmiah peserta didik (Sunariyati, Agung, \& Dantes, 2014).

Penerapan Model PBL dengan pemberian biografi ilmuwan diharapkan memberikan kesempatan kepada mahasiswa untuk mengembangkan keahliannya dengan meniru sikap pantang menyerah ilmuwan. Selain itu cara ini juga akan melahirkan dan memunculkan sikap mahasiswa untuk mencari suatu penjelasan (Toharidin, 2011). Sikap tersebut dalam pembelajaran fisika dinamakan dengan sikap ilmiah.

Sikap ilmiah merupakan sikap kecenderungan dalam pengambilan tindakan sesuai metode ilmiah dalam menyelesaikan suatu masalah. Sikap ilmiah merupakan salah satu kemampuan ilmuwan saat mereka melakukan kegiatan sebagai ilmuwan terhadap cerminan produk dan proses sains (Sodikin., 2015) (Wijaya, Medriati, \& Swistoro, 2018). Sikap ilmiah 
merupakan sikap yang perlu dimiliki oleh seorang ilmuan, yang mencakup: kemampuan belajar yang besar dan rasa ingin tahu yang tinggi, jujur, tidak dapat menerima kebenaran tanpa bukti, toleran, terbuka, optimis, skeptis, pemberani, dan kreatif atau swadaya (Azizah, 2019) (Jasin, 2010). Selain itu, Sikap-sikap ilmiah merupakan perubahan tingkah laku yakni teliti, jujur, berpikir rasional, obyektif, non-bias dan kritis (Astawa, Sadia, \& Suastra, 2015) (Natalina, Mahadi, \& Suzane, 2013).

Salah satu sikap ilmiah yaitu berpikir kritis yang memiliki hubungan sangat kuat dengan motivasi belajar (Nugraha, Suyitno, \& Susilaningsih, 2017). Motivasi belajar dapat meningkat dengan penggunaan model PBL (Arief, Maulana, \& Sudin, 2016) (Wirda, Gani, \& Khaldun, 2015). Motivasi belajar merupakan perubahan pada diri peserta didik untuk mendorong peserta didik untuk melakukan pencapaian dalam menyelesaikan tugas akademik (Harapit, 2018). Berdasarkan uraian, di atas maka tertarik untuk melihat pada sisis yang berbeda mengenai penerapan model PBL dengan pemberian biografi ilmuwan sebagai upaya meningkatkan sikap ilmiah dan motivasi belajar mahasiswa.

\section{METODE}

Penelitian ini menggunakan pendekatan Kuantitatif dan Jenis penelitian deskriptif. Metode penelitian yang digunakan adalah pre-experimental design dengan desain pretest-postest satu kelompok atau one-group pretest-postest design (Sugiyono, 2012). Peneliti mengambil mahasiswa semester I yang memprogram mata kuliah Fisika Dasar I tahun ajaran 2019/2020 di Tadris Fisika Fisika Jurusan PMIPA FTIK IAIN Palangka Raya sebagai populasi penelitian. Peneliti mengambil seluruh populasi menjadi partisipan penelitian.

Teknik pengumpulan data yang digunakan dalam penelitian ini antara lain: metode angket untuk mengetahui sikap ilmiah dan motivasi belajar. Analisis angket sikap ilmiah dan motivasi belajar siswa menggunakan analisis statistik deskriptif rata-rata berdasarkan nilai yang diberikan berdasarkan hasil angket siswa yang telah dijawab. Adapun indikator sikap ilmiah yang diamati ditunjukkan tabel 1 .

Tabel 1 Indikator Sikap Ilmiah

\begin{tabular}{|c|c|}
\hline Sikap Ilmiah & Indikator \\
\hline \multirow[t]{3}{*}{ A. Ingin tahu } & 1. Aktif bertanya. \\
\hline & 2. Aktif mencari jawaban atau informasi. \\
\hline & 3. Aktif menjawab pertanyaan. \\
\hline \multirow[t]{3}{*}{ B. Jujur } & 1. Tidak melakukan manipulasi data. \\
\hline & 2. Mengambil keputusan berdasarkan fakta. \\
\hline & 3. Tidak mencampur fakta dengan opini \\
\hline \multirow[t]{3}{*}{ C. Kreatif } & $\begin{array}{l}\text { 1. Mengemukakan pendapat baru dalam menjawab } \\
\text { atau memecahkan masalah. }\end{array}$ \\
\hline & $\begin{array}{l}\text { 2. Menguraikan pendapat baru berdasarkan hasil } \\
\text { pengamatan. }\end{array}$ \\
\hline & 3. Menunjukkan laporan berbeda dari orang lain. \\
\hline \multirow[t]{3}{*}{ D. Tekun } & $\begin{array}{l}\text { 1. Membaca prosedur kegiatan percobaan pada LKS } \\
\text { sebelum melakukan percobaan. }\end{array}$ \\
\hline & $\begin{array}{l}\text { 2. Melanjutkan percobaan dengan sunguh-sungguh } \\
\text { meskipun mengalami kesulitan. }\end{array}$ \\
\hline & $\begin{array}{l}\text { 3. Melengkapi suatu kegiatan walaupun teman yang } \\
\text { lain sudah selesai. }\end{array}$ \\
\hline
\end{tabular}




\begin{tabular}{ll}
\hline E. Kerjasama & $\begin{array}{l}\text { 1. Menunjukkan sikap berpartisipasi aktif dalam } \\
\text { kelompok. }\end{array}$ \\
& $\begin{array}{l}\text { 2. Membantu temannya yang kesulitan mencari data. } \\
\text { 3. Mengerjakan tugas sesuai pembagian kerja } \\
\text { kelompok. }\end{array}$ \\
\hline Adan
\end{tabular}

Adaptasi (Herabudin, 2010) dan (Toharidin, 2011)

Adapun indikator motivasi belajar Indikator motivasi belajar dapat diklasifikasikan sebagai berikut: (1) adanya hasrat dan keinginan berhasil; (2) adanya dorongan dan kebutuhan dalam belajar; (3) adanya harapan dan cita-cita masa depan; (4) adanya penghargaan dalam belajar; (5) adanya kegiatan yang menarik dalam belajar; (6) adanya lingkungan belajar yang kondusif, sehingga memungkinkan seseorang mahasiswa dapat belajar dengan baik (Hamzah, 2006). Kriteria yang digunakan untuk mendeskripsikan ratarata penelitian dari hasil pengamatan sikap ilmiah dan motivasi belajar yaitu:

1 = Kurang baik

2 = Cukup baik

$3=$ Baik

4 = Sangat baik

Rentang tiap kategori ditetapkan menggunakan persamaan statistik yang disesuaikan dengan data dan aspek yang diamati.

Interval $=\frac{\text { Skor maksimal }- \text { skor minimal }}{\text { Jumlah Aspek }}$

Peningkatan hasil sikap ilmiah dan motivasi belajar dianalisis menggunakan n-gain yaitu:

$$
\text { (n) } g=\frac{\text { skor posttest }- \text { skor pretest }}{\text { skor ideal }- \text { skor pretest }}
$$

Kategori n-gain menurut Hake (1999) yang kemudian dimodifikasi yaitu sebagai berikut (Sundayana, 2014):

$0,70 \leq \mathrm{g} \leq 100$ : Tinggi

$0,30 \leq \mathrm{g}<0,70$ : Sedang

$0,00<\mathrm{g}<0,30:$ Rendah

$\mathrm{g}=0,00 \quad$ : Tidak terjadi peningkatan

$-1,00 \leq \mathrm{g}<0,00$ : Terjadi Penurunan

\section{HASIL DAN PEMBAHASAN}

Sikap Ilmiah Mahasiswa setelah PBL dengan diterapkan pemberian biografi ilmuwan pada mata kuliah Fisika Dasar I

Sikap ilmiah merupakan sikap yang ditunjukkan para ilmuwan saat melakukan kegiatan ilmiah terkait dengan profesinya (Toharidin, 2011). Sikap ilmiah didukung sepenuhnya oleh pendekatan dan metode ilmiah yang sudah diakui oleh para ilmuwan. Sikap ilmiah merupakan perluasan kemampuan yang digunakan peneliti untuk mencari kebenaran realistik. Sikap ilmiah berpedoman pada paradigma tentang kebenaran indrawi yang positif karena akan lebih membuktikan relevansi antara teori dan realitas secara apa adanya (Herabudin, 2010). Sikap ilmiah merupakan sikap yang perlu dimiliki oleh seorang ilmuan, yang mencakup: kemampuan belajar yang besar dan rasa ingin tahu yang tinggi, jujur, tidak dapat menerima kebenaran tanpa bukti, toleran, terbuka, optimis, skeptis, pemberani, dan kreatif atau swadaya (Azizah, 2019) (Jasin, 2010) . Selain itu, Sikap-sikap ilmiah merupakan perubahan tingkah laku yakni teliti, jujur, berpikir rasional, obyektif, non-bias dan kritis (Astawa, Sadia, \& Suastra, 2015) (Natalina, Mahadi, \& Suzane, 2013). Indikator Sikap Ilmiah pada penelitian ini dibatasi pada sikap rasa ingin tahu, jujur, kreatif, tekun dan 
bekerjasama. Hasil Sikap Ilmiah mahasiswa pre-test dan post-test pada PBL dengan pemberian biografi ilmuwan pada mata kuliah Fisika Dasar dapat dilihat pada tabel 2 berikut:

Tabel 2. Rata-rata Sikap Ilmiah Mahasiswa

\begin{tabular}{cccc}
\hline Pretest & Postest & Gain & N gain \\
\hline 8,182 & 56,182 & 48 & 0,523 \\
\hline
\end{tabular}

Sikap ilmiah diukur melalui melalui angket sebelum dan setelah diterapkan PBL dengan pemberian biografi ilmuwan pada mata kuliah Fisika Dasar. Analisis Sikap ilmiah mahasiswa diterapkan PBL dengan pemberian biografi ilmuwan pada mata kuliah Fisika Dasar I memperoleh rata-rata pretest sikap ilmiah sebesar 8,182 dan rata-rata postest sikap ilmiah sebesar 56,182 dengan nilai Gain sebesar 48 ditunjukkan Tabel 2.

Tabel 2 menunjukkan terdapat perubahan sikap ilmiah yang berarti setelah diterapkan PBL dengan pemberian biografi ilmuwan dengan nilai $N$-Gain rata-rata sebesar 0,523 dengan kategori sedang. Sikap ilmiah mengalami peningkatan setelah diterapkan model PBL pada pembelajaran. Hal ini sejalan dengan hasil penelitian model PBL berpengaruh terhadap sikap ilmiah peserta didik (Sunariyati, Agung, \& Dantes, 2014) (Wijaya, Medriati, \& Swistoro, 2018) (Asnaeni, Lestari, \& Atmojo, 2017) (Fitriyanti, Farida, \& Zikri, 2020).

\section{Motivasi Belajar Mahasiswa setelah PBL dengan diterapkan pemberian biografi ilmuwan pada mata kuliah Fisika Dasar I}

Hakikat motivasi belajar adalah dorongan eksternal dan internal pada mahasiswa yang sedang belajar untuk melakukan perubahan tingkah laku (CLEOPATRA, 2015). Indikator motivasi belajar dapat diklasifikasikan sebagai berikut: (1) adanya hasrat dan keinginan berhasil; (2) adanya dorongan dan kebutuhan dalam belajar; (3) adanya harapan dan cita-cita masa depan; (4) adanya penghargaan dalam belajar; (5) adanya kegiatan yang menarik dalam belajar; (6) adanya lingkungan belajar yang kondusif, sehingga memungkinkan seseorang siswa dapat belajar dengan baik (Hamzah, 2006). Rekapitulasi angket Motivasi belajar mahasiswa pre-test dan post-test pada PBL dengan pemberian biografi ilmuwan pada mata kuliah Fisika Dasar I dapat dilihat seperti pada tabel 3 berikut: 
Tabel 3. Rata-rata Motivasi Belajar Mahasiswa

\begin{tabular}{|c|c|c|c|}
\hline Pretest & Postest & Gain & N gain \\
\hline 6,864 & 49,636 & 42,772 & 0,459 \\
\hline
\end{tabular}

Motivasi belajar diukur melalui melalui angket sebelum dan setelah diterapkan PBL dengan pemberian biografi ilmuwan pada mata kuliah Fisika Dasar. Analisis Motivasi belajar mahasiswa diterapkan PBL dengan pemberian biografi ilmuwan pada mata kuliah Fisika Dasar I memperoleh rata-rata pretest motivasi belajar sebesar 6,864 dan rata-rata postest motivasi belajar sebesar 49,636 dengan nilai Gain sebesar 42,772 ditunjukkan Tabel 3.

Tabel 3 menunjukkan terdapat perubahan motivasi belajar yang berarti setelah diterapkan PBL dengan pemberian biografi ilmuwan dengan nilai $\mathrm{N}$-Gain rata-rata sebesar 0,459 dengan kategori sedang. Motivasi belajar mengalami peningkatan setelah diterapkan PBL dengan pemberian biografi ilmuwan. Hal ini sejalan dengan hasil penelitian yaitu motivasi berpengaruh positif setelah diterapkan model PBL pada pembelajaran (Arief, Maulana, \& Sudin, 2016) (Wirda, Gani, \& Khaldun, 2015). Model PBL merupakan salah satu model pembelajaran yang memberikan pengaruh yang positif terhadap peningkatan prestasi belajar fisika khususnya peserta didik yang memiliki motivasi belajar tinggi. (Lestari, 2012)

\section{KESIMPULAN}

Berdasarkan hasil analisis data dan pembahasan dapat diambil suatu kesimpulan sebagai berikut : (1) Terdapat peningkatan kemampuan sikap ilmiah dengan menerapkan PBL dengan pemberian biografi ilmuwan pada mata kuliah Fisika Dasar I kategori sedang dengan nilai Ngain 0,523 dan (2) Terdapat peningkatan motivasi belajar dengan menerapkan PBL dengan pemberian biografi ilmuwan pada mata kuliah Fisika Dasar I kategori sedang dengan nilai Ngain 0,459. Dapat,disimpulkan terdapat peningkatan sikap ilmiah dan motivasi belajar setelah menerapkan PBL dengan pemberian biografi ilmuwan pada mata kuliah Fisika Dasar I.

\section{SARAN}

Adapun saran berdasarkan kendala dialami pada penelitian antara lain pembelajaran dengan menerapkan PBL dengan pemberian biografi ilmuwan pada mata kuliah Fisika Dasar I ini perlunya persiapan dari pendidik untuk menyiapkan bahan biografi ilmuwan sesuai tema dan mengaitkan dengan model PBL yang diterapkan ke peserta didik dan kesadaran peserta didik untuk memiliki motivasi seperti ilmuwan yang pantang menyerah.

\section{UCAPAN TERIMAKASIH}

Ucapan terima kasih kepada IAIN Palangka Raya yang telah memberikan hibah penelitian individu pada tahun 2019.

\section{DAFTAR PUSTAKA}

Arief, H. S., Maulana, \& Sudin, A. (2016). Meningkatkan Motivasi Belajar Melalui Pendekatan Problem-Based Learning (Pbl). Jurnal Pena Ilmiah, 1(1), 141-150.

Asnaeni, Lestari, L., \& Atmojo, I. R. (2017). Penerapan Model Pembelajaran Problem Based Learning (PBL) Untuk Meningkatkan Sikap Ilmiah Pada Pembelajaran IPA Siswa Sekolah Dasar. Didaktika Dwija Indria, 5(5).

Astawa, I. M., Sadia, W., \& Suastra, W. (2015). Pengaruh Model Pembelajaran Berbasis Proyek Terhadap Sikap Ilmiah Dan Konsep Diri Siswa SMP. e- Journal Program Pascasarjana Universitas Pendidikan Ganesha Program Studi Pendidikan IPA, 5(2), $1-11$. 
Azizah, R. O. (2019). Kajian Metode Eksperimen Terhadap Sikap Ilmiah Siswa Pada Pembelajaran IPA. Prosiding Seminar Nasional PGSD UST. 1, pp. 262-266. yogyakarta: UST Press.

CLEOPATRA, M. (2015). Pengaruh Gaya Hidup Dan Motivasi Belajar Terhadap Prestasi Belajar Matematika. Jurnal Formatif, 5(2), 168-181.

Fauziah, R., Abdullah, A. G., \& Hakim, D. L. (2013). Pembelajaran Saintifik Elektronika Dasar Berorientasi Pembelajaran Berbasis Masalah. INVOTEC, 9(2), 165-178.

Fitriyanti, Farida, \& Zikri, A. (2020). Peningkatan Sikap Dan Kemampuan Berpikir Ilmiah Siswa Melalui Model PBL di Sekolah Dasar. Jurnal Basiced, 4(2), 491-497.

Gunada, I. W., Sahidu, H., \& Sutrio, S. (2015). Pengembangan Perangkat Pembelajaran Fisika Berbasis Masalah untuk Meningkatkan Hasil Belajar dan Sikap Ilmiah Mahasiswa. Jurnal Pendidikan Fisika dan Teknologi, 1(1), 38-46.

Hamzah. (2006). Teori Motivasi dan Pengukurannya. Jakarta: Bumi Aksara.

Harapit, S. (2018). Peranan Problem Based Learning (PBL) Terhadap Kemampuan Pemecahan Masalah Dan Motivasi Belajar Peserta Didik. Jurnal Pendidikan Tambusai, 4(2), 912-917.

Herabudin. (2010). Ilmu Alamiah Dasar. Bandung: Pustaka Setia.

Jasin, M. (2010). Ilmu Alamiah Dasar. Jakarta: PT Raja Grafindo Persada.

Khoirunisa, A., Rohmadi, M., \& Yuliani, H. (2020). Penerapan Problem Based Learning Berbasis Numbered Heads Together:Dampak Hubungan Aktivitas dengan Hasil Belajar. Kappa Journal, 4(2), 165-171.

Lestari, N. N. (2012). Pengaruh Model Pembelajaran Berbasis Masalah (Problem- Based Learning) Dan Motivasi Belajar Terhadap Prestasi. Jurnal Teknologi Pembelajaran Indonesia, 1(2), 1-21.

Mayasari, T., Kadarohman, A., Rusdiana, D., \& Kaniawati, I. (2016). Apakah Model Pembelajaran Problem Based Learning Dan Project Based Learning Mampu Melatihkan Keterampilan Abad 21? Jurnal Pendidikan Fisika dan Keilmuan (JPFK), $2(1), 48-55$.

Natalina, M., Mahadi, I., \& Suzane, A. C. (2013). enerapan Model Pembelajaran Inkuiri Terbimbing (Guided Inquiry) untuk Meningkatkan Sikap Ilmiah dan Hasil Belajar Biologi Siswa Kelas XI IPA SMA Negeri 5 Pekanbaru Tahun Ajaran 2011/2012. Prosiding Seminar FMIPA Universitas Lampung (pp. 83-92). Lampung: UNILA.

Nugraha, A. J., Suyitno, H., \& Susilaningsih, E. (2017). Analisis Kemampuan Berpikir Kritis Ditinjau dari Keterampilan Proses Sains dan Motivasi Belajar melalui Model PBL. Journal of Primary Education, 6(1), 35-43. 
Priyambodo, E., Wiyarsi, A., \& Sari, R. L. (2012). Pengaruh Media Pembelajaran Interaktif Berbasis Web Terhadap Motivasi Belajar Mahasiswa. Jurnal Kependidikan: Penelitian Inovasi Pembelajaran, 42(2), 99-109.

Rofiqoturrohmah, A. (2019). penggunaan layanan informasi biografi tokoh dalam bimbingan kelompok untuk meningkatkan motivasi belajar pada siswa kelas $x$ di smk tri sukses natar tahun ajaran 2018/2019. universitas lampung, Prodi Bimbingan dan Konseling Fakultas Keguruan Dan Ilmu Pendidikan. Lampung: Universitas Lampung. Retrieved from http://digilib.unila.ac.id/id/eprint/58880

Shinta, S., Fatmawati, S., \& Nasir, M. (2020). Komparasi Model Problem Based Learning Dan Discovery Learning Terhadap Hasil Belajar Ditinjau Dari Kemampuan Awal. Kappa Journal, 4(1), 16-22.

Sinurat, R. (2017). Studi Eksploratif Persepsi Guru Dan Calon Guru Fisika Terhadap Mata Kuliah Sejarah Fisika. Universitas Negeri Semarang. Semarang: Universitas Negeri Semarang. Retrieved from http://lib.unnes.ac.id/id/eprint/32435

Sodikin. (2015). Penerapan Pembelajaran Berbasis Masalah Melalui Metode Eksperimen dan Demonstrasi Ditinjau dari Kemampuan Menggunakan Alat Ukur dan Sikap Ilmiah Siswa. Jurnal Ilmiah Pendidikan Fisika, 4(2), 255-267.

Sugiyono. (2012). Metode Penelitian Administrasi. Bandung: Alfabeta.

Sunariyati, N. L., Agung, A. A., \& Dantes, N. (2014). Pengaruh Model Pembelajaran Berbasis Masalah (Problem Based Learning/PBL) Terhadap Hasil Belajar, Keterampilan Berfikir Kritis Dan Sikap Ilmiah Dalam Pembelajaran Fisika Pada Siswa Kelas Xi IPA SMA Negeri 1 Kuta Tahun Pelajaran 2014/2015. Jurnal Administrasi Pendidikan Indonesia, 5(1).

Sundayana, R. (2014). Statistika Penelitian Pendidikan. Bandung: Alfabeta.

Toharidin, U. (2011). Membangun Literasi Sains Peserta Didik. Bandung: Humaniora.

Wajdi, B. (2018). Penerapan Model Pembelajaran Problem Based Learning (PBL) Menggunakan Media Power Point Pada Pembelajaran Fisika. Kappa Journal, 1(2), 918.

Wijaya, S. A., Medriati, R., \& Swistoro, E. (2018). Pengaruh Model Pembelajaran Berbasis Masalah terhadap KemampuanPemecahan Masalah Fisika dan Sikap IlmiahSiswa di SMAN2 Kota Bengkulu. Jurnal Kumparan Fisika, 1(5), 28-35.

Wirda, W., Gani, A., \& Khaldun, I. (2015). Penerapan Pembelajaran Model Problem Based Learning (Pbl) Untuk Meningkatkan Keterampilan Proses Sains Dan Motivasi Belajar Siswa Pada Materi Alat-Alat Optik. Jurnal Pendidikan Sains Indonesia, 3(2), 131142. 
Yuliani, H. (2012). Pembelajaran Fisika dengan Pendekatan Keterampilan Proses dengan Metode Eksperimen dan Demonstrasi Ditinjau dari Sikap Ilmiah dan Kemampuan Analisis. Surakarta: UNS.

Yunita, N., Zahara, L., \& Sahidi, K. (2020). Pengaruh Model Problem Based Learning (PBL) Melalui Lesson Study Terhadap Kemampuan Berpikir Kritis Siswa. Kappa Journal, 4(2), 233-239. 